\title{
Catalytic Hydrodeoxygenation of Methyl-Substituted Phenols: Correlations of Kinetic Parameters with Molecular Properties
}

\author{
F. E. Massoth, ${ }^{\dagger}$ P. Politzer, ${ }^{\dagger, \S}$ M. C. Concha, ${ }^{\dagger, \S}$ J. S. Murray, ${ }^{\dagger, \S}$ J. Jakowski, ${ }^{\dagger, »}$ and \\ Jack Simons ${ }^{*,+, \sharp}$ \\ Departments of Chemical Engineering and Chemistry, University of Utah, Salt Lake City, Utah 84112, and \\ Department of Chemistry, University of New Orleans, New Orleans, Louisiana 70148
}

Received: December 15, 2005; In Final Form: April 12, 2006

\begin{abstract}
The hydrodeoxygenation of methyl-substituted phenols was carried out in a flow microreactor at $300{ }^{\circ} \mathrm{C}$ and $2.85 \mathrm{MPa}$ hydrogen pressure over a sulfided $\mathrm{CoMo} / \mathrm{Al}_{2} \mathrm{O}_{3}$ catalyst. The primary reaction products were methylsubstituted benzene, cyclohexene, cyclohexane, and $\mathrm{H}_{2} \mathrm{O}$. Analysis of the results suggests that two independent reaction paths are operative, one leading to aromatics and the other to partially or completely hydrogenated cyclohexanes. The reaction data were analyzed using Langmuir-Hinshelwood kinetics to extract the values of the reactant-to-catalyst adsorption constant and of the rate constants characterizing the two reaction paths. The adsorption constant was found to be the same for both reactions, suggesting that a single catalytic site center is operative in both reactions. Ab initio electronic structure calculations were used to evaluate the electrostatic potentials and valence orbital ionization potentials for all of the substituted phenol reactants. Correlations were observed between (a) the adsorption constant and the two reaction rate constants measured for various methyl-substitutions and (b) certain moments of the electrostatic potentials and certain orbitals' ionization potentials of the isolated phenol molecules. On the basis of these correlations to intrinsic reactantmolecule properties, a reaction mechanism is proposed for each pathway, and it is suggested that the dependencies of adsorption and reaction rates upon methyl-group substitution are a result of the substituents' effects on the electrostatic potential and orbitals rather than geometric (steric) effects.
\end{abstract}

\section{Introduction}

As a result of increasing environmental concerns, catalytic hydrotreating has become an important process for the removal of sulfur and nitrogen from petroleum. Also, heterocyclic compounds containing sulfur and nitrogen can cause corrosion and poisoning of noble metal catalysts, so it is important to remove them to preserve the catalyst's lifetime. The potential use of synthetic oils derived from coal, oil shale, and tar sands would render the hydrotreating of oxygen-containing compounds, mostly phenols, which are present in relatively large amounts in fuels refined from coal ${ }^{1}$ equally important. It is on the latter class of reactions that the present paper is focused.

The catalytic hydrodeoxygenation (HDO) of oxygen-containing compounds generally involves two reaction paths, one leading to an aromatic product and the other to aliphatic hydrocarbons..$^{2,3,4,5}$ For phenols, it is believed that the first path (hydrogenolysis) entails a direct cleavage of the $\mathrm{C}-\mathrm{O} \sigma$ bond (this is labeled the $\mathrm{COH}$ reaction). The second path involves a hydrogenation of phenol's aromatic ring (this is labeled the HYD reaction), possibly to form a cyclohexanol intermediate that subsequently rapidly converts to cyclohexene or cyclohexane products. These two paths are illustrated in Figure 1 where the aromatic and fully hydrogenated products are labeled B and C, respectively.

From work on sulfur-containing compounds, it is well-known that difficulty arises in achieving high hydrodesulfurization (HDS) conversions (i.e., sulfur removal) with conventional feeds because of the presence of "unreactive" sulfur compounds that

* To whom correspondence should be addressed. E-mail: simons@chem.utah.edu.

† Department of Chemical Engineering, University of Utah

$\div$ Department of Chemistry, University of Utah.

$\S$ Department of Chemistry, University of New Orleans.

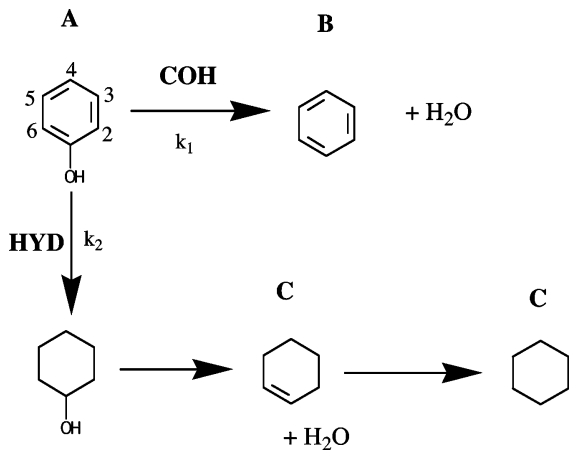

Figure 1. Reaction network for the HDO of phenol showing the numbering convention for the substituents, as well as the $\mathrm{COH}$ and HYD reaction paths and their products $B$ and $C$.

have been identified as alkyl-substituted dibenzothiophenes in which the alkyl group is adjacent to the sulfur atom. As a result, considerable study has been devoted to the effects of methyl substitution on the rates of hydrodesulfurization of model compounds such as thiophene, ${ }^{6}$ benzothiophene, ${ }^{7}$ and dibenzothiophene. ${ }^{8,9}$ In these cases, compounds containing methyl groups adjacent to the sulfur atom are found to have lower activity, which generally has been attributed to steric hindrance of the adsorption to the catalyst through the sulfur atom. However, Meille et al ${ }^{10}$ suggested that the reduced activity of, for example, 2,6-dimethyl dibenzothiophene compared to the parent (i.e., unsubstituted compound) reflected a lower intrinsic reaction rate rather than a decrease in adsorption. Although it has not been determined if these findings apply to oxygencontaining compounds such as phenols, such studies suggest that properties other than steric effects may play important roles in determining overall reaction rates and yields. It is with this in mind that we examined the relationships between experi- 
mentally observed adsorption and reaction rate constants and electronic properties of the isolated (i.e., not in contact with any catalyst) methyl-substituted phenol molecules treated in this paper. Of course, the $\mathrm{COH}$ and $\mathrm{HYD}$ reactions occur under the influence of a catalyst, but the postulate we attempt to explore in the present work is that characteristics intrinsic to the substituted phenols (e.g., orbital ionization energies and molecular electrostatic potentials) might be the determining factors in governing the relative rates of the $\mathrm{COH}$ and $\mathrm{HYD}$ reactions among the various substituted phenols.

There have been a number of earlier investigations of the effect of alkyl substituents on the HDO reactivity of phenolic compounds, and a methyl group adjacent to the hydroxyl group was found to result in lower activity. ${ }^{2,3,11-13}$ Again, this has been taken to indicate that steric effects are important in the reactivity of methyl-substituted phenols, but as we mentioned above and discuss later, it may be intrinsic electronic-structure differences rather than steric hindrance that control the rates.

Our suggestion that intrinsic electronic properties of the reactant molecules can alter the rates of reactions is not new. Linear free energy relationships have been used to relate reaction rates or adsorption equilibria in heterogeneous catalysis to intrinsic properties of the reactants or the catalysts. For example, Mochida and Yoneda ${ }^{14}$ have done so for the dealkylation of alkylbenzenes over cracking catalysts and Beranek and Kraus ${ }^{15}$ for the hydrodealkylation of alkylbenzenes over Ni/alumina. Other examples are presented in the review by Kraus. ${ }^{16}$ However, there have been only a limited number of studies of correlations between reactivity and properties of the reactants under hydrotreating conditions. $\mathrm{Nag}^{17}$ linked the hydrogenation rates of various aromatic compounds to their lowest ionization potentials, as approximated by the magnitudes of the energies of their highest-occupied molecular orbitals (HOMOs). It was proposed that the ionization potential relates to the activation energy of the hydrogenation. Moreau et al, ${ }^{4}$ in a detailed study of the reactions of various substituted benzenes over sulfided $\mathrm{NiMo} / \mathrm{Al}_{2} \mathrm{O}_{3}$ catalyst, reported correlations of the first-order rate constants for both hydrogenolysis to benzene and hydrogenation to cyclohexane with the resonance substituent constant of the reactant. $\mathrm{Ma}$ et $\mathrm{al}^{18}$ correlated the relative activity of direct hydrogenolysis of sulfur-containing compounds with the electron density on the sulfur atoms. Isoda et $\mathrm{al}^{19}$ found a better relationship between the relative hydrogenolysis rate constants and the energies of the orbital lying five levels below the HOMO (i.e, the HOMO-5 which is a lone pair orbital on the sulfur atom). For a series of methyl-substituted indoles, Kim and Massoth ${ }^{20}$ found correlations between rates of hydrogenolysis and the electrostatic potential at the nitrogen atom and between rates of hydrogenation and ionization potentials. In a followup study with quinolines, ${ }^{21}$ the hydrogenolysis rate constants were again related to electrostatic potentials at the nitrogens. However, prior to this work, no similar investigations involving phenols have been found in our examination of the literature.

In summary, one of the aims of the present work is to determine the effects of methyl substituents on the HDO reactivity of methyl-substituted phenols and to attempt to relate the relative reactivities among various methyl-substituted species to intrinsic properties of the reactant molecules as determined from electronic structure calculations. The properties we considered relate to the electrostatic potential in the molecules, as well as to the electron-binding energies of various valence molecular orbitals. Finally, we should mention that in discussing our results on methyl-substituted phenols, the numbering system shown in Figure 1 is used.

\section{Experimental Procedures}

The catalyst consisted of $4 \% \mathrm{CoO}$ and $15 \% \mathrm{MoO}_{3}$ supported on alumina (Akzo Chemicals) with a surface area of $235 \mathrm{~m}^{2} / \mathrm{g}$. The extrudates were crushed and sieved to 40- to 60-mesh particles. Reactions were carried out in a fixed-bed reactor at $300{ }^{\circ} \mathrm{C}$ and $2.85 \mathrm{MPa}$ under vapor-phase conditions. A $0.26 \mathrm{~g}$ sample of catalyst, mixed with $5 \mathrm{~cm}^{3}$ of glass beads, was presulfurized with a $10 \% \mathrm{H}_{2} \mathrm{~S} / 90 \% \mathrm{H}_{2}$ mixture (by volume) under atmospheric pressure and at $400{ }^{\circ} \mathrm{C}$ for $2 \mathrm{~h}$. For the phenol runs, the liquid feed consisted of $0.5 \mathrm{wt} \%$ of a given phenol (Aldrich, highest purity) and $1.0 \mathrm{wt} \%$ dimethyl disulfide (to maintain the catalyst in the sulfided state) dissolved in $n$-heptane or $n$-decane. The hydrogen-flow rate and liquid-flow rate were varied proportionally so that constant feed concentrations were maintained throughout the runs. After the catalyst was aged for 2 days under reaction conditions, the catalyst activity remained essentially constant over $300 \mathrm{~h}$.

Six liquid samples taken at several space times were analyzed by gas chromatography on a $0.32 \times 36.6 \mathrm{~cm}$ stainless steel column packed with $6 \%$ OV-17 on $100-120$-mesh WHP Chromosorb with a flame ionization detector and temperature programming of $10^{\circ} \mathrm{C} / \mathrm{min}$. Individual products were identified by comparison with available pure reference samples. Molar GC factors were determined using available samples of phenols and their reaction products.

The major organic compounds found in samples from runs with phenolic feeds were unreacted feed, as well as aromatic (species B in Figure 1), cyclohexene, and cyclohexane (species $\mathrm{C}$ in Figure 1) analogues. The concentrations of such species provided data that were analyzed to determine the kinetic parameters relating to the reaction steps shown in Figure 1 using Scientist II (a product of MicroMath Scientific Software), on the basis of the following set of Langmuir-Hinshelwood equations

$$
\begin{gathered}
\frac{\mathrm{d} A}{\mathrm{~d} \tau}=-\frac{k_{1} K_{\mathrm{A}} A+k_{2} K_{\mathrm{A}} A}{\left(1+C_{0} K_{\mathrm{A}} A\right)^{n}} \\
\frac{\mathrm{d} B}{\mathrm{~d} \tau}=\frac{k_{1} K_{\mathrm{A}} A}{\left(1+C_{0} K_{\mathrm{A}} A\right)^{n}} \\
\frac{\mathrm{d} C}{\mathrm{~d} \tau}=\frac{k_{2} K_{\mathrm{A}} A}{\left(1+C_{0} K_{\mathrm{A}} A\right)^{n}}
\end{gathered}
$$

where $A, B$, and $C$ represent mole fractions of the phenolic feed, the aromatic analogue (benzene), and the hydrocarbon analogues (cyclohexene plus cyclohexane), respectively, as noted in Figure 1. $K_{\mathrm{A}}$ is the equilibrium constant for reactant species A adsorbing onto the catalyst, $k_{1}$ is the rate constant for the formation of aromatics (via the $\mathrm{COH}$ path), $k_{2}$ is the rate constant for the formation of hydrocarbons (via the HYD path), $C_{0}$ is the feed concentration of A, $\tau$ is the space-time variable, and $n$ is the order of inhibition. The Scientist II program is used to obtain best-fit values for the adsorption and rate constants, as well as errors, for the parameters for a given set of concentration (mole fraction) versus space-time data. We will have more to say later about how the data we obtained do indeed fit the kinetic scheme of Figure 1 and thus allow us to use eqs $1-3$ to extract relevant adsorption and rate constants.

\section{Computational Methods}

Our use of computational chemistry techniques focuses on identifying quantitative molecular properties of the reactant- 
substituted phenol molecules that correlate with the experimentally measured quantities such as rate and adsorption constants. The two primary classes of calculated properties are the electrostatic potential-derived quantities and the electronic ionization potentials relating to both oxygen lone pair and aromatic $\pi$ molecular orbitals. Our reasons behind considering these particular properties relate to our desire to understand the mechanisms of the adsorption and reaction processes in terms of what regions (e.g, aromatic ring $\pi$ or oxygen lone pair) of the molecule are involved and if the molecule interacts with catalytic sites in a flat (i.e., through the aromatic $\pi$ orbitals) or perpendicular (i.e., primarily through the oxygen atom) manner in the two reaction steps.

Prior to the evaluation of either class of property, the molecules' geometries were optimized (to determine their minimum-energy structures) using aug-cc-pVDZ basis sets ${ }^{22}$ at the Hartree-Fock level of theory. These calculations also produced the estimates (we used the outer-valence Greens function $\left(\mathrm{OVGF}^{23}\right)$ data that includes the effects of electron correlation) of the ionization potentials (IPs) for the highestoccupied molecular orbital (HOMO) and for lower-energy orbitals which we denote HOMO-1, HOMO-2, etc. The Gaussian 03 program suite ${ }^{24}$ was employed for all of these computations. We again stress that the properties thereby obtained relate to the isolated substituted phenols, not to the molecules in the presence of any catalyst. The relevance of these computations to the adsorption and reaction rates of the molecules in the presence of catalyst relies on our being able to show that the trends (with methyl-substitution position and number) in adsorption and reaction parallel trends in these computed properties. If these trends do correlate, as we later demonstrate, this suggests that it is the variations in the intrinsic electronic properties of the reactant molecules that govern how the molecule interacts with the catalyst which, in turn, determines the adsorption and rate outcomes.

In addition to the IPs noted above, we also computed, using the density functional B3PW91/6-31G* procedure within the Gaussian program suite, several quantities that relate to the molecule's electrostatic potential, $V(\mathbf{r})$, defined as

$$
V(\mathbf{r})=\sum_{\mathrm{A}} \frac{Z_{\mathrm{A}}}{\left|\mathbf{R}_{\mathrm{A}}-\mathbf{r}\right|}-\int \frac{\rho\left(\mathbf{r}^{\prime}\right) \mathrm{d} \mathbf{r}^{\prime}}{\left|\mathbf{r}^{\prime}-\mathbf{r}\right|}
$$

Here, $Z_{\mathrm{A}}$ is the charge on nucleus $\mathrm{A}$, which is located at $\mathbf{R}_{\mathrm{A}}$, $\rho\left(\mathbf{r}^{\prime}\right)$ is the electron density at the position $\mathbf{r}^{\prime}$ that produces an electrostatic potential $V(\mathbf{r})$ at the location $\mathbf{r}$. The sum in eq 4 runs over all of the nuclei in the molecule. $V(\mathbf{r})$ computed on a surface (denoted $\mathrm{S}$ ) surrounding the molecule and defined as the 0.001 electrons $/ b_{b o h r}{ }^{3}$ contour of $\rho(\mathbf{r})$ has $\operatorname{proven}^{25}$ to be particularly useful for analyzing noncovalent interactions such as physical adsorption, which may play an important role in the reactions studied here. It is through the value of the potential computed along the surface $\mathrm{S}$, which we label $V_{\mathrm{S}}(\mathbf{r})$, that any species encountering our substituted phenols initially interact with these molecules. Rather than computing and viewing values of the $V_{\mathrm{S}}(\mathbf{r})$ function, we have found it efficient to characterize the main features of $V_{S}(\mathbf{r})$ by computing certain statistical averages. Those that we use in the present work include $\bar{V}_{\mathrm{S}}{ }^{+}$ and $\bar{V}_{\mathrm{S}}{ }^{-}$, which are the averages of $V(\mathbf{r})$ taken over many points

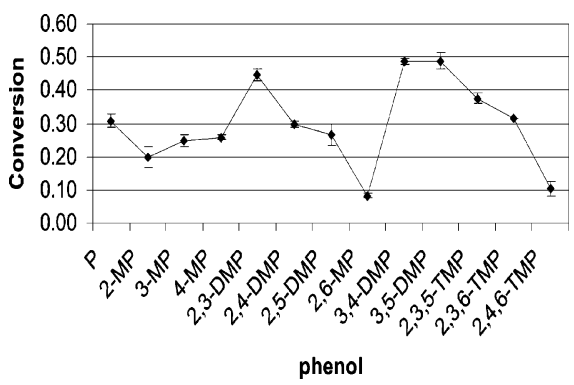

Figure 2. Conversions (mole fraction) of phenol compounds as a function of methyl positions on phenol at a space time of $0.57 \mathrm{~kg} \mathrm{~min} /$ $\mathrm{m}^{3}$.

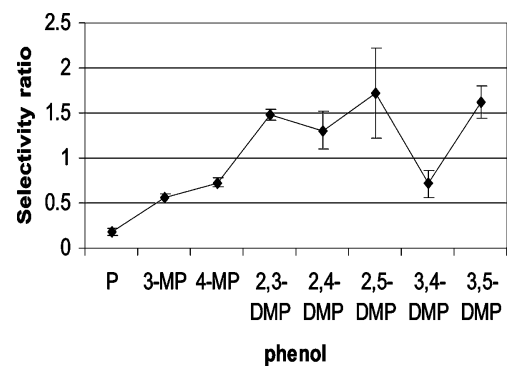

Figure 3. Aromatic selectivity ratio vs methyl group positions on phenol.

( $p$ and $n$, respectively) on the surface $S$ where $V_{\mathbf{S}}(\mathbf{r})$ is positive or negative, respectively

$$
\begin{aligned}
& \bar{V}_{\mathrm{S}}^{+}=\frac{1}{p_{j=1}^{p}}\left|V_{\mathrm{S}}^{+}\left(\mathbf{r}_{j}\right)\right| \\
& \bar{V}_{\mathrm{S}}^{-}=\frac{1}{n_{j=1}} \sum_{j=1}^{n}\left|V_{\mathrm{S}}^{-}\left(\mathbf{r}_{j}\right)\right|
\end{aligned}
$$

Because the electrostatic potential is negative in regions of space near the oxygen atom and above and below the aromatic ring (i.e., where the $\pi$ orbitals have their highest density), $\bar{V}_{\mathrm{S}}{ }^{-}$relates to the magnitude of this potential in these regions of the molecule. Likewise, $\bar{V}_{\mathrm{S}}{ }^{+}$relates to the magnitude of the electrostatic potential in regions of the molecule where this potential is positive (e.g., near the $\mathrm{H}$ atom of the $\mathrm{OH}$ group).

\section{Results}

Reactivities. Figure 2 displays the overall conversion of the phenolic compounds versus the position of the methyl groups. The error bars denote $95 \%$ confidence intervals (CIs) on the conversion data (analogously for other figures shown in this paper). There appears to be a slight lowering in conversion when the methyl group is on a carbon adjacent to the $\mathrm{OH}$ group (e.g., in 2-MP), especially when methyl groups appear in both adjacent positions (2,6-DMP and 2,4,6-TMP). However, the presence of a methyl group in the 3-position seems, in some cases, to override the latter effect (e.g., consider 2,3-DMP vs 2-MP or 2,3,6-TMP vs 2,4,6-TMP). In fact, the 3 -position has a positive effect on conversion in all cases except for 3-MP versus the parent phenol itself. Positions 4 and 5 appear to have little effect on conversions. These results are in general agreement with those reported in the literature, ${ }^{2,3,12,13,26}$ even though reaction conditions may be different in many of the studies.

In Figure 3, the aromatic selectivity ratio is plotted for the methyl positions. The selectivity is defined as the ratio of the aromatic compound yield (B) of the $\mathrm{COH}$ reaction to the hydrogenated compounds $(\mathrm{C})$ and was found to be independent 

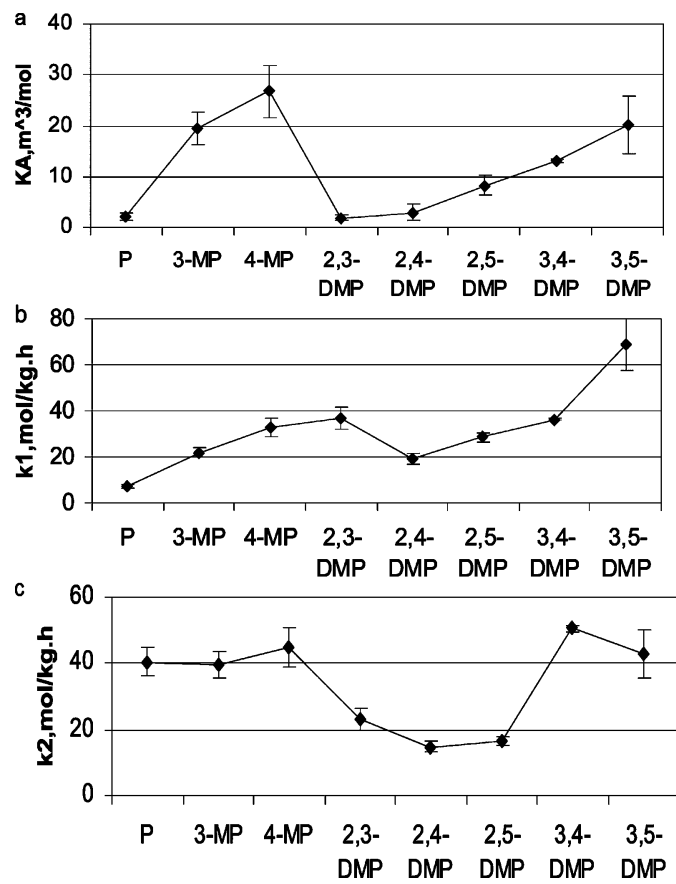

Figure 4. Effect of methyl position on (a) adsorption constant, $K_{\mathrm{A}}$, (b) $\mathrm{COH}$ rate constant, $k_{1}$, and (c) HYD rate constant, $k_{2}$.

of space-time. From Figure 3, it is evident that the aromatic pathway is favored as methyl groups are added. Thus, the addition of each methyl increases the selectivity ratio by about 3-fold (except for 3,4-DMP) and is relatively independent of position. Experimental analytical problems prevented us from obtaining reliable selectivities for the 2-MP and 2,6-DMP compounds (because of the low conversion values) and for the trimethyl-phenols (because of poor separation of isomers), so data for these species are not included in Figure 3.

Adsorption and Reaction Rate Parameters. Equations 1-3 with the value $n=2$ in the denominator were used to obtain the parameters $K_{\mathrm{A}}, k_{1}$, and $k_{2}$ for the various phenols. Because only six space times were used with each phenol, there was considerable error in some cases. Figure $4 \mathrm{a}$ displays the dependence of the adsorption constant, $K_{\mathrm{A}}$, on the locations of the methyl groups. It is quite evident that phenol-containing methyl groups in the 2-position (and phenol itself) exhibit relatively lower adsorption constants compared to other positions (i.e., the 3- and 4-positions). Although this result would seem to suggest that the low adsorption constant of phenols containing a methyl group in the 2-position is due to steric hindrance to adsorption, the results of parameter correlations discussed later indicate this is not necessarily the case.

Plots of the rate constants, $k_{1}$, for the $\mathrm{C}-\mathrm{O}$ bond cleavage reaction path $(\mathrm{COH})$ leading to aromatic products, as well as those of $k_{2}$ for the aromatic ring hydrogenation (HYD) path eventually leading to saturated products (see Figure 1), versus the methyl position are shown in Figure $4 \mathrm{~b}$ and c. For the $\mathrm{COH}$ reaction, the $k_{1}$ rate constant for phenol itself is lowest and that for 3,5-DMP highest, while the others show intermediate values. It is significant that the presence of 2-methyl in conjunction with a 3-, 4-, or 5-methyl group has little effect on this rate constant. Thus, despite low adsorption constants (Figure 4a), the intrinsic $\mathrm{COH}$ reactivity of these combinations seems not to be affected by a methyl group in the 2-position.

For the HYD reaction, the trend in the $k_{2}$ rate constants is quite different from that of $k_{1}$ in that a methyl group in the 2-position significantly depresses $k_{2}$. In fact, there appear (Figure $4 \mathrm{c})$ to be two groups of $k_{2}$ values: one group having higher $k_{2}$ but no 2-methyl substitution and another with lower $k_{2}$ whose members have 2-methyl substitution. In contrast to the $k_{1}$ data, the lower $k_{2}$ data (i.e., those with 2-methyl substitution) appear to reflect the lower $K_{\mathrm{A}}$ data of Figure $4 \mathrm{a}$. This would suggest a common step or active site between adsorption and hydrogenation, but as with the adsorption constant case, it does not explain why $k_{2}$ varies as it does with methyl position.

Overall, it appears that there are significant variations in the $K_{\mathrm{A}}, k_{1}$, and $k_{2}$ parameters as the location and number of substituent methyl groups are varied, but the patterns of these variations are not yet clear. However, as we suggest that our later analysis and discussion shows, these trends can indeed be understood in terms of the intrinsic electronic properties that we have computed for the reactant molecules.

\section{Discussion}

Reaction Paths. It was previously proposed that the HDO of phenols occurs by two separate reaction paths ${ }^{2,5,12,27}$ as shown in Figure 1. These two paths involve (1) a direct hydrogenolysis (aromatic $\mathrm{C}-\mathrm{O} \sigma$ bond cleavage) leading to a benzene analogue product (B) and (2) a prehydrogenation of the aromatic ring to form a cyclohexanol, followed by a rapid elimination of water to form a cyclohexene and subsequent hydrogenation to produce cyclohexane product (C). It is noted that in a study of the HDN of $o$-propylaniline (an isoelectronic analogue of 2-propylphenol), the hydrogenated intermediate propylcyclohexylamine was observed at low concentration, indicating that the prehydrogenation was the first and rate-limiting step to hydrogenated products. ${ }^{28}$ Separate reaction paths for hydrogenolysis and hydrogenation have been reported for similar hydrodesulfurization reactions ${ }^{29,30}$ and for hydrodenitrogenation reactons. ${ }^{4,20,28}$ In particular, the HDN of aniline (an isoelectronic analogue of phenol) has been much studied, with authors agreeing on two separate reaction paths. ${ }^{27,31}$

In contrast, cyclohexanone has been reported as a major product together with cyclohexane when phenol was reacted over reduced supported metal catalysts at atmospheric pressure. ${ }^{32,33}$ However, cyclohexanone has not been reported as being found in reaction products over typical sulfided hydrotreating catalysts at elevated hydrogen pressure such as we employed here.

The experimental data showing that aromatic selectivity is independent of space-time and conversion is also consistent with parallel competing reaction paths. As noted earlier, the aromatic path becomes more favored with an increase in the number of methyl groups. It is significant that this trend is independent of the methyl-group position and especially noteworthy that methyl substitution in the 2-position appears to have little "special" effect on the selectivity.

Kinetics. The course of the reaction as a function of spacetime indicated (from concentration vs space-time plots) that the reaction was strongly inhibited by adsorption of the reactant because the optimal $n$ parameter in eqs $1-3$ was found to be $n$ $=2$. That is, we verified, by kinetic analysis of the data using the Langmuir-Hinshelwood $(\mathrm{L}-\mathrm{H})$ treatment involving eqs $1-3$, which in all cases, gave the best fits to the data with a square in the denominator terms $(n=2)$. In a few cases, $n=$ 1 fit but with larger error, and in many cases, no satisfactory fit was obtained for $n=1$. A similar kinetic expression (i.e., with $n=2$ ) was reported for phenol HDO at low pressure. ${ }^{34}$ In a kinetic study of the HDO of benzofuran, the best $\mathrm{L}-\mathrm{H}$ rate equation for the hydrogenolysis path also gave $n=2$, although a pseudo-first-order fit was obtained for the hydrogenation path. ${ }^{35}$ A squared denominator term was also found for the 


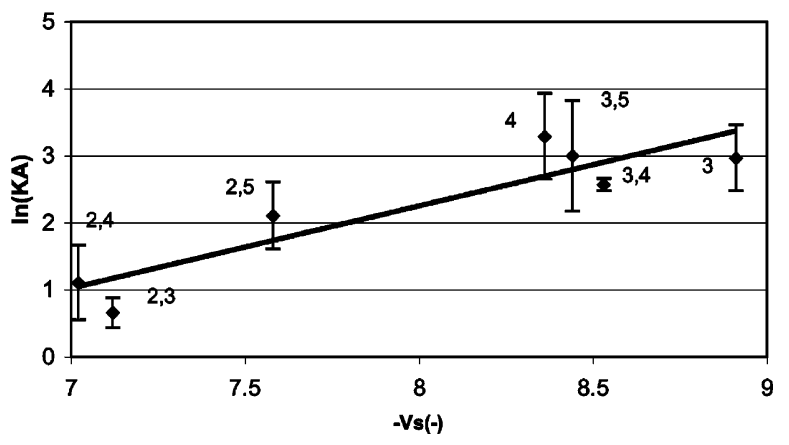

Figure 5. Correlation of adsorption constant $K_{\mathrm{A}}$ with the magnitude of the average surface negative electrostatic potential $-\bar{V}_{\mathrm{S}}{ }^{-} \cdot R^{2}=0.82$ with the parent compound phenol omitted. The numbers denote the methyl positions on phenol.

catalytic dealkylation of alkylaromatic compounds, ${ }^{36}$ as well as hydrodenitrogenation of indole ${ }^{37}$ and quinoline. ${ }^{38}$ A squared denominator term, in conjunction with a first-order (in reactant) rate law in the numerator, has been interpreted as involving the reaction between an adsorbed species and an active site.

The above kinetic analysis assumes only one adsorption constant, $K_{\mathrm{A}}$, that applies to both the $\mathrm{COH}$ and $\mathrm{HYD}$ reactions. Our data were also analyzed using two separate adsorption constants, $K_{\mathrm{B}}$ and $K_{\mathrm{C}}$, for each reaction, as discussed in the Appendix. However, our results demonstrate that, within the 95\% CI's, the adsorption constants for the two reactions are essentially identical. We will have more to say later (in the Catalytic Sites and Mechanisms section) about what this observation may mean for the mechanisms by which the $\mathrm{COH}$ and HYD reactions occur, but for now we use this only to explain why our eqs $1-3$ use the same $K_{\mathrm{A}}$ value for adsorption leading to both $\mathrm{COH}$ and HYD.

Correlations with Molecular Properties. The electrostatic potential and orbital energy parameters calculated for the different phenols were examined for trends reflecting those of the adsorption constant, $K_{\mathrm{A}}$, hydrogenolysis rate constant, $k_{1}$, and hydrogenation rate constant, $k_{2}$. Because these coefficients are expected to relate to energies (of adsorption or of activation) in an Arrhenius-like manner, correlations between the natural logarithm of the kinetic parameters and the computational quantities were examined. Examples of the best fits are given in Figures 5, 6, and 8. Although the statistical $R^{2}$ values are only modest (e.g., $0.7-0.8$ ) in most cases, the data mostly fit well within the $95 \%$ confidence intervals as shown in these figures.

Figure 5 shows that for the adsorption constant $K_{\mathrm{A}}$; the parameter $\bar{V}_{\mathrm{S}}^{-}$gave a good fit to the data but only when the parent phenol was excluded from the fit $\left(R^{2}=0.82\right)$. The $\bar{V}_{\mathrm{S}}{ }^{-}$ parameter is a measure of the average electrostatic potential over regions of the surface of the molecule where $V(\mathbf{r})$ is negative. Moreover, the correlation with $-\bar{V}_{\mathrm{S}}{ }^{-}$is positive meaning that the larger $-\bar{V}_{\mathrm{S}}{ }^{-}$is the larger is the adsorption constant. This suggests that adsorption of the reactant phenols to the catalyst involves binding to regions of the molecule where the electrostatic potential is negative. The highly negative parts of the molecules are near the oxygen atom (most negative) and above and below the aromatic ring in the regions of the $\mathrm{C}=\mathrm{C} \pi$ bonds (second most negative), so it is not possible from this correlation to infer whether adsorption occurs in a flat manner (that would involve the $\mathrm{C}=\mathrm{C} \pi$ bonds and the oxygen atom's out-of-plane lone pair orbital) or perpendicular (that could occur at the oxygen atom's in-plane lone pair orbital).

That the adsorption constant is found to be significantly lower when methyl groups are adjacent to the $\mathrm{O}$ atom (see Figure 4)
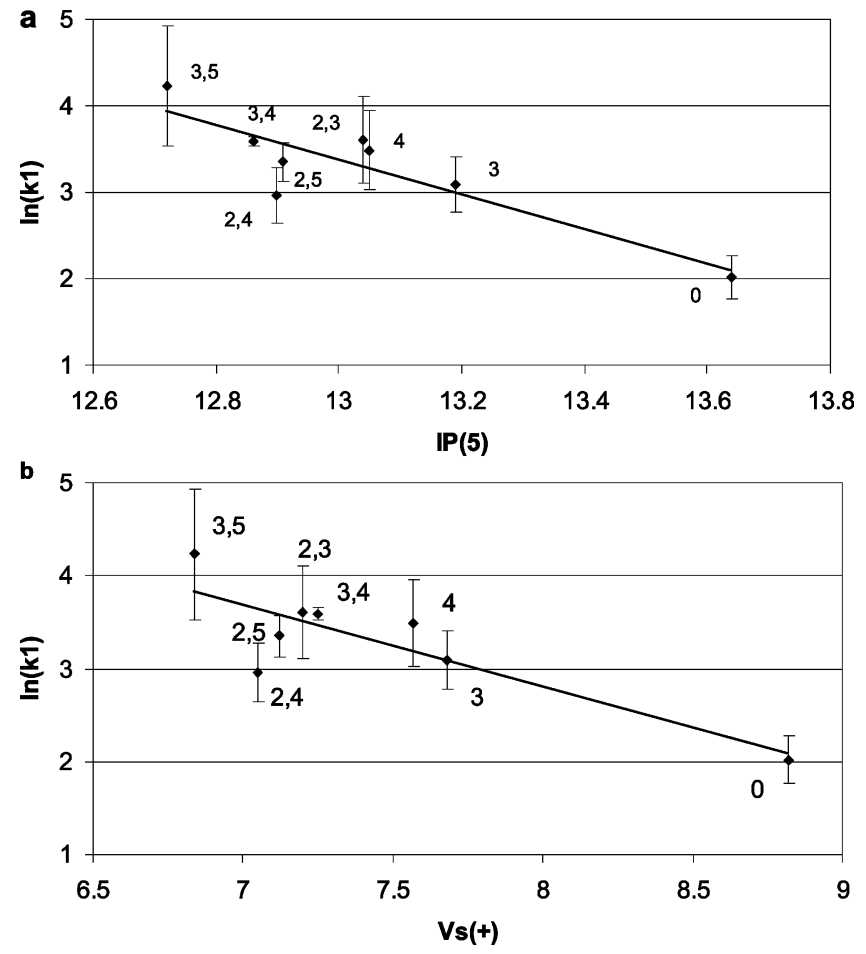

Figure 6. Correlation of $\mathrm{COH}$ rate constant $k_{1}$ with (a) ionization potential at the HOMO-5 level IP(5) in electronvolts, $R^{2}=0.76$, and with (b) the average surface positive electrostatic potential parameter $\bar{V}_{\mathrm{S}}{ }^{+}$parameter, $R^{2}=0.73$. The numbers denote the methyl positions on phenol, where 0 denotes phenol itself.

might be attributed to steric hindrance to perpendicular adsorption through the $\mathrm{O}$ atom. However, the good correlation obtained between $K_{\mathrm{A}}$ and the parameter $-\bar{V}_{\mathrm{S}}{ }^{-}$suggests that methyl substitution in the ortho position produces a smaller $-\bar{V}_{\mathrm{S}}{ }^{-}$, and this, in turn, causes $K_{\mathrm{A}}$ to be smaller.

As shown in Figure 6, the $\mathrm{COH}$ rate constant, $k_{1}$, and the ionization potentials (IPs) of the $\mathrm{HOMO}-5$ (the in-plane oxygen lone pair orbital shown in Figure 7) gave the best fit of the data $\left(R^{2}=0.76\right)$ even when the parent compound is included. The ionization potential of the HOMO-2 (the out-of-plane oxygen lone pair orbital shown in Figure 7) also gave a good fit with $R^{2}=0.73$ when the parent compound is included. Moreover, the fact that $k_{1}$ increases as the IPs decrease suggests that the more difficult it is to remove an electron from one of the oxygen lone pair orbitals, the slower will be the $\mathrm{COH}$ rate.

As indicated in Figure 7, only the IPs of HOMO-2 and HOMO-5 showed correlations with $R^{2}$ values exceeding 0.7 , thus suggesting the electron densities in these two orbitals rather than in any of the other orbitals are involved in the $\mathrm{COH}$ process. Because $\mathrm{HOMO}-2$ and $\mathrm{HOMO}-5$ are not the orbitals with the lowest ionization potentials (that is the HOMO), these findings suggest that it is not just the ease of removing an electron from an orbital that affects the reaction rates but the chemical nature (e.g., $\mathrm{HOMO}-2$ and $\mathrm{HOMO}-5$ are the oxygen lone pair orbitals) of the orbitals.

Also shown in Figure 6 is a plot of the $k_{1}$ data against the average value of the electrostatic potential, $V$, in regions (primarily near the $\mathrm{O}-\mathrm{H}$ group's hydrogen) where this potential is positive $\bar{V}_{\mathrm{S}}{ }^{+}$for which the fit has $R^{2}=0.73$. This is not surprising given the fact that methyl groups are known to donate electron density (i.e., when acting in an inductive manner), and any donation of electron density (i.e., negative charge) toward the $\mathrm{OH}$ group would both decrease the oxygen atom's IPs and make the potential near the $\mathrm{H}$ atom less positive. We also note 


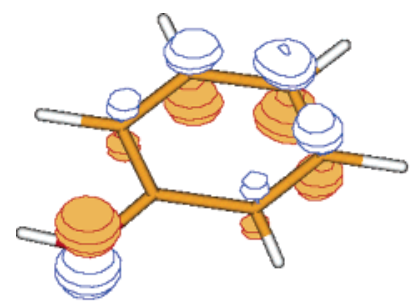

HOMO-2

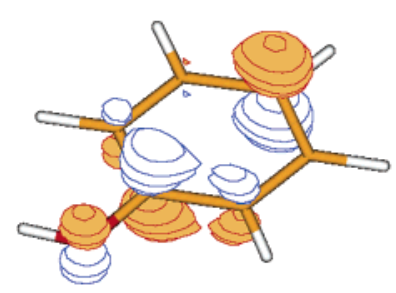

HOMO

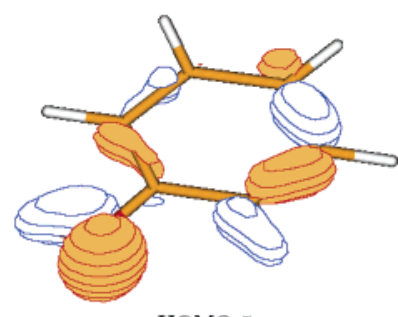

HOMO-5

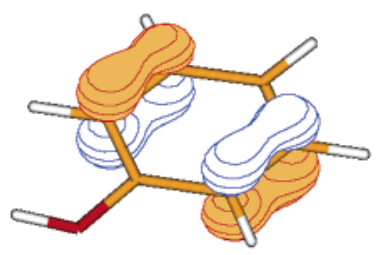

HOMO-1

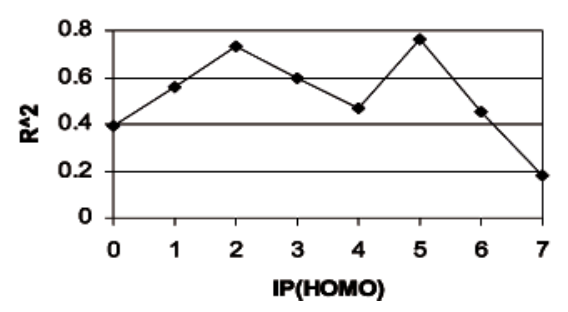

Figure 7. Plots of four of the molecular orbits of phenol whose properties may relate to various adsorption or rate constants (top) and statistical $R^{2}$ values for $\ln \left(k_{1}\right)$ vs IP correlations for the eight highestoccupied molecular orbitals (bottom).

that correlations between $\bar{V}_{\mathrm{S}}{ }^{+}$and the IPs of both HOMO-2 and HOMO-5 were observed with $R^{2}=0.95$, which is consistent with the methyl groups' effects on the $\mathrm{OH}$ group.

The trend of decreasing $k_{1}$ with increasing $\mathrm{O}$ lone-pair IP suggests the oxygen atom is acting as a Lewis base in the ratelimiting step of this reaction; the higher the IPs, the weaker a Lewis base the oxygen atom becomes and thus the weaker the binding of this $\mathrm{O}$ atom to any catalyst Lewis acid site. However, we cannot tell from these data alone whether the in-plane or out-of-plane $\mathrm{O}$ lone-pair orbital is serving as the Lewis base site. Thus, again it is not possible to conclude whether this reaction proceeds with the phenol bound to the catalyst in a flat or perpendicular manner.

In studies on heterocyclic sulfur compounds, Ma et al. ${ }^{18}$ reported a correlation for the relative activity of the direct hydrogenolysis with the computed electron density at the $\mathrm{S}$ atom. Isoda et al. ${ }^{19}$ found a correlation between the relative rate constants for HDS of methyldibenzothiophenes and the ionization potential of the HOMO-5 orbital, which they attributed to a $\mathrm{S}-\sigma$ lone-pair orbital that bonds to the catalyst. Our suggestion that $k_{1}$ is related to the Lewis base strength of an oxygen lone pair orbital is in line with these findings on heterocyclic sulfur compounds.

Correlations between the HYD rate constant $k_{2}$ (Figure 8) and $-\bar{V}_{\mathrm{S}}{ }^{-}\left(R^{2}=0.78\right)$ were observed, even when the parent compound is included. The fact that $-\bar{V}_{\mathrm{S}}{ }^{-}$correlates with both $K_{\mathrm{A}}$ and $k_{2}$ is especially noteworthy because, as noted earlier, the effects of methyl substitution in the 2-position are similar for $K_{\mathrm{A}}$ and $k_{2}$. The general pattern shown in Figure 8 is for the rate coefficient $k_{2}$ to become larger as $-\bar{V}_{\mathrm{S}}{ }^{-}$increases. Because the negative regions of our molecules tend to be near the $\mathrm{O}$ atom and above and below the aromatic ring near the $\mathrm{C}=\mathrm{C} \pi$ bonds, enhancement in the HYD rate may relate to how negative the potential is near the $\mathrm{O}$ atom or in the $\mathrm{C}=\mathrm{C} \pi$ bonds.

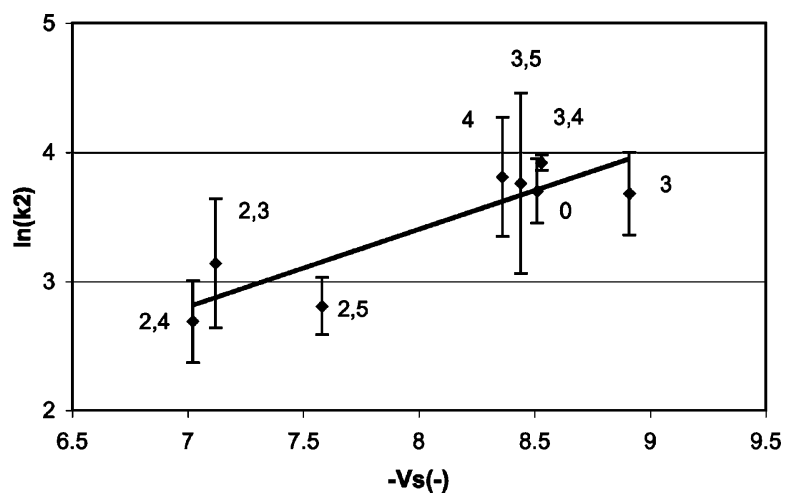

Figure 8. Correlation of HYD rate constant $k_{2}$ with the magnitude of the average surface negative electrostatic potential $-\bar{V}_{\mathrm{S}}{ }^{-} \cdot R^{2}=0.78$. The numbers denote the methyl positions on phenol.

The above correlations demonstrate that, in each case, one or more intrinsic electronic property of the isolated reactant phenol can be directly related to either adsorption or one of the two reaction rates. Thus, the adsorption and rate data obtained for reactants containing a methyl group in the 2-position are perhaps understandable in terms of the electronic properties of the isolated reactant molecules as reflected in these intrinsic properties, rather than by geometric steric effects.

Catalytic Sites and Mechanisms. Studies on the characterization of hydroprocessing catalysts have been recently reviewed in detail. ${ }^{39}$ The catalyst used in the present study, which is typical of these catalysts, consists of multiple slabs of $\mathrm{MoS}_{2}$ with adjoining $\mathrm{Co}$ atoms supported on the alumina surface. The slabs are believed to be mostly of hexagonal shape. Three sides consist of lattice surface $\mathrm{S}$ atoms covering the underlying Mo atoms (S-edge) and are believed to be catalytically inactive. On the opposite three sides of the ideal $\mathrm{MoS}_{2}$ slabs, mostly Mo atoms are exposed (Mo-edge). However, recent studies have indicated that under "typical" hydroprocessing conditions, the Mo edge would be essentially covered by adsorbed $\mathrm{S}$ or $\mathrm{SH}$, although the presence of $\mathrm{Co}$ or $\mathrm{Ni}$ could lead to stable coordinatively unsaturated sites (CUS). ${ }^{40}$ Nevertheless, there is contrary evidence that some exposed Mo CUS sites ( $\mathrm{S}$ vacancies) could exist on the Mo edge, depending on the ratio of the $\mathrm{H}_{2} \mathrm{~S}$ to $\mathrm{H}_{2}$ partial pressures. ${ }^{41}$ For example, Lauritsen et al. ${ }^{42}$ report at an $\mathrm{H}_{2} \mathrm{~S} / \mathrm{H}_{2}$ ratio of 0.07 "lower-sulfur coverage on the Mo edges", and Sun et al. ${ }^{43}$ present a plot of "relative probability" coverage versus $\mathrm{H}_{2} \mathrm{~S} / \mathrm{H}_{2}$ ratio. Under our reaction conditions, the $\mathrm{H}_{2} \mathrm{~S} / \mathrm{H}_{2}$ ratio was 0.0027 , which corresponds to Sun's et al. description of about half of the Mo edge covered by $\mathrm{S}$ or $\mathrm{SH}$ and half containing about one vacancy per five $\mathrm{S}$. These findings, based mainly on DFT calculations, seem to confirm earlier speculations relative to the presence of vacancies. ${ }^{39}$ The Mo-edge has been proposed to be active for the HYD reactions ${ }^{44}$ while $\mathrm{S}$ vacancy sites may be favorable for adsorption through a heteroatom leading, for example, to hydrogenolysis.

In earlier studies of phenols reacting along the aromatic path $(\mathrm{COH})$, it has been assumed that the reactant is adsorbed via a bond involving the heteroatom at a catalyst sulfur vacancy site. For the hydrogenation path, a flat adsorption via aromatic $\pi$ bonding at several sulfur vacancies was assumed ${ }^{3}$. The latter study, as well as one by Laurent and Delmon, ${ }^{5}$ showed that an increase in $\mathrm{H}_{2} \mathrm{~S}$ partial pressure depressed the yield of the aromatic path but not of the hydrogenation path, which suggested that separate sites are involved. However, it is also possible that a combined site is involved, in which adsorption binds through both the aromatic ring and the $\mathrm{O}$ atom simulta- 

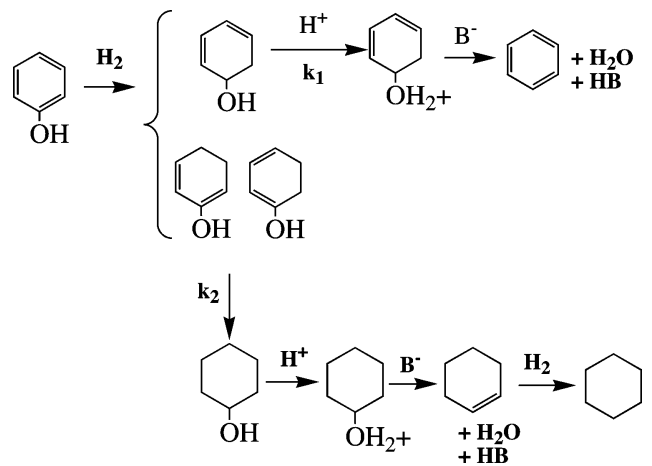

Figure 9. Proposed reaction paths for the $\mathrm{COH}$ (top path) and HYD (bottom path) reactions.

neously. For example, Moreau et al. ${ }^{4,45}$ proposed a dual site consisting of adjacent electron-withdrawing and electrondonating sites to accommodate adsorption of the aromatic part and the heteroatom part of the molecule. Such a dual-site center would help explain our finding of a single adsorption constant for both reactions. We therefore propose that the $\mathrm{COH}$ site consists of a vacancy site associated with Mo (or $\mathrm{Co}$ ) and that adjacent HYD sites have $\mathrm{S}$ or $\mathrm{SH}$ groups. Thus, adsorption of phenol would cover both sites of the center. The inhibiting effect of $\mathrm{H}_{2} \mathrm{~S}$ on the aromatic path could be the result of competitive adsorption with phenol on the vacancy ( $\mathrm{COH}$ site), while phenol adsorption on the neighboring $\mathrm{S}$ or $\mathrm{SH}$ groups (HYD sites) would be little affected.

In a study of the hydrogenation of analogues of benzene, Volter et al. ${ }^{46}$ considered that the reaction proceeded first through adsorption forming a $\pi$ complex, followed by conversion to an adsorbed $\sigma$-bonded species. The latter hydrogenates to a cyclohexadiene intermediate, which eventually fully hydrogenates to cyclohexane. A cyclodiene intermediate was also proposed for the hydrogenation of pyridine based on molecular orbital studies. ${ }^{47}$ For dibenzothiophene, partially hydrogenated intermediates have been proposed by Singhal et al., ${ }^{48}$ Meille et al., ${ }^{10}$ Bataile et al., ${ }^{49}$ and Pokorny and Zdrazil. ${ }^{50}$

Although we propose an $\mathrm{H}$-intermediate in the $\mathrm{COH}$ path, a direct hydrogenolysis path to an aromatic cannot be ruled out. Thus, two independent paths were invoked in the hydrodeoxygenation of phenols ${ }^{2,3}$ and for 1-naphthol. ${ }^{51}$ Such a direct C-heteroatom splitting has also been proposed for the HDN of o-propylaniline 28 and of indole and for the HDS of dibenzothiophene. ${ }^{36,52}$ It should be pointed out, however, that in these cases, no evidence was provided for the existence of the direct path.

Proposed Mechanism. On the basis of the above considerations and our experimental observations presented earlier, we offer the proposed mechanism shown in Figure 9 after the phenol molecule has adsorbed onto the catalyst. The first step involves a rapid (thus not rate-limiting) hydrogenation of one double bond leading to a dihydrophenol intermediate with the equilibrium lying very far to left. We suggest this as the first step in part because it is known that cleavage of the $\mathrm{C}-\mathrm{O} \sigma$ bond is considerably more energy-intensive when this bond is attached to an aromatic ring that delocalizes the out-of plane oxygen lone-pair orbital. Removal of this delocalization in the first step facilitates subsequent cleavage of the $\mathrm{C}-\mathrm{O} \sigma$ bond and allows the subsequent reaction to proceed via either of the two paths (COH or HYD) as discussed below.

For that fraction of the phenol species whose first doublebond hydrogenation is more distant from the $\mathrm{C}-\mathrm{O}$ bond and thus does not remove the delocalization (e.g., the two species hydrogenated in the 3,4- or 2,3-positions (or equivalent) in

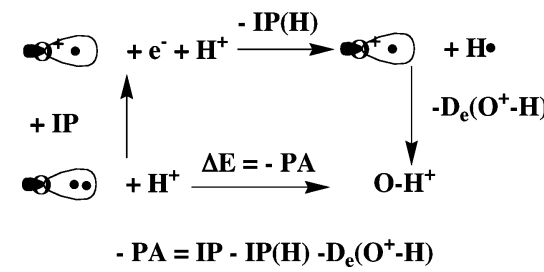

Figure 10. Thermodynamic cycle showing relations among proton affinity (PA) of the oxygen lone-pair orbital, its ionization potential (IP), and the $\mathrm{O}^{+}-\mathrm{H}$ bond dissociation energy, $D_{\mathrm{e}}\left(\mathrm{O}^{+}-\mathrm{H}\right)$. These relations are used to explain correlations between IP values and $k_{1}$ values.

Figure 9), subsequent reaction likely occurs via the HYD path (relating to $k_{2}$ ) discussed immediately below. For the fraction hydrogenated in the 1,2- or 1,6-positions, $\mathrm{C}-\mathrm{O}$ bond cleavage (relating to $k_{1}$ ) is more favorable for the reason explained above, so HYD can occur. So, the common dihydrophenol intermediate can then react further along either of two paths.

(1) Dehydration can take place (with the rate-limiting step relating to the measured $k_{1}$ values), reforming the aromatic ring and eliminating $\mathrm{H}_{2} \mathrm{O}$. We offer further details about our view of the mechanism of this $\mathrm{COH}$ path below.

(2) Alternatively, further hydrogenation to cyclohexanol (with the rate-limiting step relating to the measured $k_{2}$ values) is followed by elimination of water to form a cyclic alkene which subsequently can be hydrogenated to yield cyclohexane. This is the HYD path.

Note that the back-reactions of cyclohexanol to the dihydophenol intermediate and of this intermediate to phenol are necessary to establish reversible paths between phenol and cyclohexanol. Let us now elaborate on the detailed steps likely to be involved in the two pathways introduced above.

In the direct hydrogenolysis $(\mathrm{COH})$ path reforming the aromatic ring and eliminating water, cleavage of the $\mathrm{C}-\mathrm{O} \sigma$ bond is suggested to occur through adsorption of the phenol onto a vacancy site of the catalyst via the $\mathrm{O}$ atom, analogous to what was suggested for the $\mathrm{C}-\mathrm{S}$ cleavage in the HDS of thiophene. ${ }^{53}$ This requires a vacancy (Lewis acid site) on the catalyst to accept an electron pair of the $\mathrm{O}$ atom to facilitate the $\mathrm{C}-\mathrm{O}$ bond cleavage. Earlier, we explained that under our $\mathrm{H}_{2} \mathrm{~S} / \mathrm{H}_{2}$ conditions, the catalyst surface should have many such vacancy sites available. These assumptions about how the molecule binds to the catalyst are motivated by our observation that the IPs of the two oxygen-centered orbitals (HOMO-2 and $\mathrm{HOMO}-5$ ) correlate most strongly with the $\mathrm{COH}$ rate constant $k_{1}$ in a manner that gives smaller $k_{1}$ values for larger IPs (i.e., the $\mathrm{O}$ atom has a lower proton affinity when its IP is higher). On a molecular level, this mechanism can be viewed as following along the top path shown in Figure 9. After adsorption, the catalyst's $\mathrm{H}^{+}$attacks the oxygen center to generate the $-\mathrm{OH}_{2}{ }^{+}$species, after which a Lewis base $\mathrm{B}^{-}$(likely $\mathrm{HS}^{-}$) effects a $\beta$-hydrogen elimination to eliminate $\mathrm{H}_{2} \mathrm{O}$ and $\mathrm{HB}$ and to generate a new double bond thus reconstituting the aromatic ring. We note that a similar set of steps for the conversion of aniline to benzene has been described by Prins. ${ }^{54}$

For such a mechanism, one would expect a decrease in the rate when the ability of the $\mathrm{O}$ atom to react with $\mathrm{H}^{+}$(i.e., its proton affinity) decreases. Assuming the rate of this step is, in turn, related to the energy change $\Delta E$ accompanying the reaction, one must consider how $\Delta E$ relates to the proton affinity (PA) of the $\mathrm{O}$ atom. As the thermodynamic cycle shown in Figure 10 illustrates, O-atom proton affinity values within closely related compounds (i.e., those having nearly identical $\mathrm{O}-\mathrm{H}$ bond strengths, $D_{\mathrm{e}}(\mathrm{O}-\mathrm{H})$, as we verified is the case for 
our phenol compounds using our quantum chemistry calculations) are found to be related to the ionization potentials (IPs) of the O lone-pair orbital: the smaller the IP, the larger the PA. Thus, in our case, we expect that the oxygen proton affinities of our phenols relate directly to the IPs of the oxygen lone pair orbitals that are protonated in the rate-limiting step: the higher the IP of the O orbital, the smaller the PA and thus the smaller the $k_{1}$. These trends are consistent with the observed decreases in the experimental $k_{1}$ values with increases in $\mathrm{O}$ lonepair orbitals' IPs as the methyl substituent location varies (see Figure 6a).

The proposed mechanism for $\mathrm{COH}$ suggests that an increase in $\mathrm{H}^{+}$concentration should even further enhance the reaction rate. However, because the rate constant for this path has been shown ${ }^{27,5}$ to decrease with increasing $\mathrm{H}_{2} \mathrm{~S}$ (which could produce some additional $\mathrm{H}^{+}$) concentration, it is most likely that $\mathrm{H}_{2} \mathrm{~S}$ reduces the rate because it is competitively adsorbing to the catalyst's vacancy sites, which is consistent with the active site for $\mathrm{COH}$ being a sulfur vacancy. Thus, it is likely that the $\mathrm{H}^{+}$ involved in $\mathrm{COH}$ is primarily coming from a Brønsted acid site of the catalyst generated by sulfiding the catalyst at reaction temperature. ${ }^{55}$

Now, let us turn to discuss the HYD pathway. As shown in the lower path in Figure 9, this reaction involves first the hydrogenation of one double bond in phenol followed by the hydrogenation of the other two $\mathrm{C}=\mathrm{C} \pi$ bonds to form a cyclohexanol, with the latter step being rate-limiting and thus relating to the $k_{2}$ rate constant. In analogy to the HDN of aniline, ${ }^{56}$ it may be supposed that the mechanism of the subsequent elimination of water from the cyclohexanol could occur by a $\beta$-hydrogen elimination as also shown in the bottom path of Figure 9. In the latter steps, an attack by a proton (the Brønsted BH site may be a catalyst SH group) occurs to form an intermediate protonated oxy species. Subsequent attack by a base (e.g., $\mathrm{HS}^{-}$) eliminates $\mathrm{H}_{2} \mathrm{O}$ and $\mathrm{H}_{2} \mathrm{~S}$ and forms cyclohexene in the $\beta$-hydrogen elimination step. Finally, further hydrogenation of cyclohexene to cyclohexane occurs. In this sequence, the initial prehydrogenation to cyclohexanol is the rate-limiting step. The failure to observe the presence of cyclohexanols under our reaction conditions indicates the rapid subsequent reactivities of these intermediates.

The rate of the path that forms (substituted) cyclohexane, described by the $k_{2}$ rate constant, is also observed to increase as the value of $-\bar{V}_{\mathrm{S}}{ }^{-}$increases. Because $\bar{V}_{\mathrm{S}}{ }^{-}$relates to the strength of the electrostatic potential in the region of the oxygen atom (i.e., where $V(\mathbf{r})$ is most negative) and near the $\mathrm{C}=\mathrm{C} \pi$ bonds (where $V(\mathbf{r})$ is also negative), the correlation with $k_{2}$ and -EnDash $V_{\mathrm{S}}{ }^{-}$suggests that the oxygen atom or the $\mathrm{C}=\mathrm{C} \pi$ bonds must be bound to the catalyst and that this binding must catalytically weaken the $\mathrm{C}=\mathrm{C} \pi$ bonds making them more susceptible to hydrogenation. Recalling that $-\bar{V}_{\mathrm{S}}{ }^{-}$also correlates with the adsorption constant $K_{\mathrm{A}}$, we conclude that adsorption involves the oxygen atom or $\mathrm{C}=\mathrm{C} \pi$ bond site or both and that this binding also weakens the $\mathrm{C}=\mathrm{C} \pi$ bonds thus enhancing $k_{2}$. Again, this observation is in line with the fact that under our $\mathrm{H}_{2} \mathrm{~S} / \mathrm{H}_{2}$ conditions, the catalyst has vacancies, as well as filled sites available: the former likely bind the oxygen and the latter can bind to and weaken the $\mathrm{C}=\mathrm{C} \pi$ bonds.

We should note that the $\beta$-hydrogen elimination process is assumed in the HYD path of Figure 9. An alternate mechanism involving nucleophilic substitution by ${ }^{-} \mathrm{SH}$, followed by hydrogenolysis has been discussed in detail by Prins ${ }^{54}$ for the aniline case. Nelson and Levy ${ }^{56}$ also point out that nucleophilic substitution can occur in cleaving $\mathrm{C}-\mathrm{N}$ bonds where the carbon occurs in an aliphatic compound. In our case, this means that the HYD path could also involve the following steps.

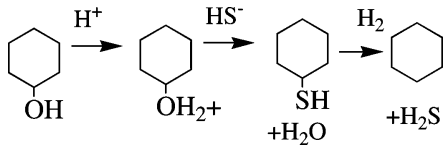

Here, the cyclohexanol is protonated, and then a base (e.g., $\mathrm{HS}^{-}$) displaces, by an $\mathrm{S}_{\mathrm{N} 2}$ reaction, the water to form the thiol, which can then rapidly react with $\mathrm{H}_{2}$ to produce the cyclohexane and $\mathrm{H}_{2} \mathrm{~S}$.

\section{Conclusions}

Analyses of the products from the hydrodeoxygenation of methyl-substituted phenols indicates that two separate reaction paths are present, one leading to an aromatic and the other to a cyclohexane, and that the adsorption constants associated with the two paths are equal, suggesting that a single reaction site center is operative in both reactions.

Correlations of the derived adsorption constant $\left(K_{\mathrm{A}}\right)$ and the hydrodeoxygenation $\left(k_{1}\right)$ and hydrogenation $\left(k_{2}\right)$ rate coefficients to molecular parameters that relate to the electrostatic potential $V(\mathbf{r})$ and to the ionization potentials of certain valence molecular orbitals of the substituted phenols are observed. Our primary correlations are as follows:

1. Coefficient $K_{\mathrm{A}}$, related to adsorption of the phenol onto the catalyst surface, increases as the magnitude (i.e., $-\bar{V}_{\mathrm{S}}{ }^{-}$) of the average electrostatic potential in regions of the molecular surface where $V(\mathbf{r})$ is negative increases. Because these regions focus primarily near the oxygen atom but also with contributions from the $\mathrm{C}=\mathrm{C} \pi$ bonds, we interpret this to mean that adsorption most likely involves the catalyst binding with the oxygen atom, although we cannot determine from these data alone whether the adsorption is flat (where the $\mathrm{C}=\mathrm{C} \pi$ bonds could also contribute to adsorption) or perpendicular because oxygen has both $\sigma$ and $\pi$ lone-pair orbitals.

2. The rate constant $k_{1}$, related to hydrodeoxygenation, increases as the ionization potentials of the oxygen $\sigma$ and $\pi$ lone-pair orbitals (HOMO-2 and HOMO-5) decrease. Noting that such ionization potentials can, in turn, be related to the oxygen atom's proton affinities suggests that the rate-limiting step in this process involves the oxygen being protonated to form species containing $-\mathrm{OH}_{2}{ }^{+}$. We also noted that $k_{1}$ correlated (albeit with significantly smaller $R^{2}$ values) with the IPs of several other occupied molecular orbitals, but the HOMO-2 and $\mathrm{HOMO}-5$ (i.e, the two lone-pair orbitals) produced more significant correlations.

3. Rate constant $k_{2}$, related to the hydrogenation process, increases as $-\bar{V}_{\mathrm{S}}-$ increases, paralleling the trends in $K_{\mathrm{A}}$. The largest contributions to $-\bar{V}_{\mathrm{S}}{ }^{-}$come from regions near the $\mathrm{O}$ atom and the $\mathrm{C}=\mathrm{C} \pi$ bonds. Noting that the oxygen out-ofplane lone-pair orbital is delocalized onto the $\mathrm{C}=\mathrm{C} \pi$ orbitals of the aromatic ring suggests that hydrogenation of the $\mathrm{C}=\mathrm{C} \pi$ bonds can be enhanced by binding of the oxygen atom to the catalyst through this orbital. That is, when the oxygen binds to the catalyst using its $\pi$ lone-pair orbital, this weakens the $\mathrm{C}=\mathrm{C}$ $\pi$ bonds and thus makes hydrogenation of these bonds more facile. In addition, in such a flat adsorption geometry, donation of electron density from the $\mathrm{C}=\mathrm{C} \pi$ bonds to the catalyst could both contribute to adsorption and weaken the $\mathrm{C}=\mathrm{C} \pi$ bonds. In contrast, if the oxygen atom were bound to the catalyst through its in-plane orbital, there is no reason to believe this would weaken the $\mathrm{C}=\mathrm{C} \pi$ bonds. 


\section{TABLE 1}

\begin{tabular}{lrcr}
\hline compound & \multicolumn{1}{c}{$K_{\mathrm{B}}$} & \multicolumn{1}{c}{$K_{\mathrm{C}}$} & \multicolumn{1}{c}{$K_{\mathrm{A}}$} \\
\hline P & $2.1 \pm 0.6$ & $2.1 \pm 4.1$ & $2.0 \pm 0.7$ \\
3-MP & $19.2 \pm 3.2$ & $15.4 \pm 7.1$ & $21.3 \pm 6.1$ \\
4-MP & $26.4 \pm 5.0$ & $26.4 \pm 11.3$ & $26.4 \pm 8.5$ \\
2,3-DMP & $1.9 \pm 0.6$ & $1.7 \pm 0.9$ & $2.4 \pm 1.6$ \\
2,4-DMP & $3.0 \pm 1.5$ & $3.1 \pm 2.73$ & $3.1 \pm 3.5$ \\
2,5-DMP & $8.2 \pm 1.9$ & $8.2 \pm 3.3$ & $8.1 \pm 5.6$ \\
3,4-DMP & $12.9 \pm 0.4$ & $12.8 \pm 1.1$ & $3.0 \pm 0.8$ \\
3,5-DMP & $19.7 \pm 5.2$ & $19.5 \pm 9.4$ & $20.0 \pm 15.1$
\end{tabular}

4. The dependencies of $K_{\mathrm{A}}, K_{\mathrm{B}}$, and $K_{\mathrm{C}}$ on methyl-group substitution may result more from electronic effects of the methyl groups than from catalyst geometric restrictions to adsorption.

Acknowledgment. The technical assistance of Mr. Jeffrey Wagner is greatly appreciated. J.S. thanks the National Science Foundation for it support through Grant CHE-0240387 and the University of Utah Center for High Performance Computing for an allocation of computer time.

\section{Appendix}

If different adsorption sites (or different adsorption constants) were involved for the two reaction paths, then eqs $1-3$ would take the following slightly modified forms

$$
\begin{gathered}
\mathrm{d} A / \mathrm{d} t=-k_{1} K_{\mathrm{B}} A / D_{\mathrm{B}}{ }^{n}-k_{1} K_{\mathrm{C}} A / D_{\mathrm{C}}{ }^{n} \\
\mathrm{~d} B / \mathrm{d} t=k_{1} K_{\mathrm{B}} A / D_{\mathrm{B}}{ }^{n} \\
\mathrm{~d} C / \mathrm{d} t=k_{1} K_{\mathrm{C}} A / D_{\mathrm{C}}{ }^{n}
\end{gathered}
$$

with

$$
\begin{aligned}
& D_{\mathrm{B}}=1+C_{\mathrm{o}} K_{\mathrm{B}} A \\
& D_{\mathrm{C}}=1+C_{\mathrm{o}} K_{\mathrm{C}} A
\end{aligned}
$$

where $K_{\mathrm{B}}$ and $K_{\mathrm{C}}$ are the adsorption constants for A adsorbing on sites $\mathrm{B}$ and $\mathrm{C}$, respectively. These equations were used in our regression analysis program to obtain values of the individual parameters, $K_{\mathrm{B}}$ and $K_{\mathrm{C}}$. As Table 1 shows, in all cases the two values for the adsorption constants are the same within experimental error and equivalent to the single value (labeled $K_{\mathrm{A}}$ ) that we use in this work (the $K$ values have units of cubic meters per mole).

\section{References and Notes}

(1) Furimsky, E. Catal. Rev. Sci. Eng. 1983, 25, 421.

(2) Odebunmi, E. O.; Ollis, D. F. J. Catal. 1983, 80, 56

(3) Gevert, B. S.; Otterstedt, J.-E.; Massoth, F. E. Appl. Catal. 1987, 31,119 .

(4) Moreau, C.; Aubert, C.; Durand, R.; Zmimta, N.; Geneste, P. Catal. Today 1988, 4, 117.

(5) Laurent, E.; Delmon, B. Ind. Eng. Chem. Res. 1993, 32, 2516.

(6) Raje, A. P.; Liaw, S. J.; Davis, B. H. Appl. Catal. 1997, 150, 319.

(7) Geneste, P.; Bonnet, M.; Graffin, P. J. Catal. 1980, 61, 115.

(8) Kwart, H.; Schuit, G. C.; Gates, B. C. J. Catal. 1980, 61, 128.

(9) Kabe, T.; Ishihara, A. Ind. Eng. Chem. Res. 1992, 31, 1577.

(10) Meille, V.; Schulz, E.; Lemaire, M.; Vrinat, M. J. Catal. 1997, 170,29

(11) Weigold, H. Fuel 1982, 61, 1021.

(12) Gevert, B. S.; Eriksson, M.; Eriksson, P.; Massoth, F. E. Appl. Catal. A 1994, 117, 151 .

(13) Okuda, H.; Arai, F.; Mizuta, S.; Ikenaga, N.; Suzuki, T. Sekiyu Gakkaishi 1997, 40, 192.

(14) Mochida, I.; Yoneda, Y. J. Catal. 1967, 7, 386.

(15) Beranek, L.; Kraus, M. Collect. Czech.. Chem. Commun. 1966, 31, 566.

(16) Kraus, M. Adv. Catal. 1980, 29, 151.

(17) Nag, N. K. Appl. Catal. 1984, 10, 53. 9,33 .
(19) Isoda, T.; Takase, Y.; Kusakabe, K.; Morooka, S. Prepr. $-A m$. Chem. Soc., Div. Petrol. Chem. 1998, 43, 575.

(20) Kim, S. C.; Massoth, F. E. J. Catal. 2000, 189, 70.

(21) Kim, S. C.; Simons, J.; Massoth, F. E. J. Catal. 2002, 212, 201.

(22) Kendall, R. A.; Dunning, T. H., Jr.; Harrison, R. J. J. Chem. Phys. 1992, 96, 6796.

(23) Ortiz, J. V. The Electron Propagator Picture of Molecular Electronic Structure. In Computational Chemistry: Reviews of Current Trends; Leszczynski, J, Ed.; World Scientific: Singapore, 1997; Vol. 2, 1-61.

(24) Frisch, M. J.; Trucks, G. W.; Schlegel, H. B.; Scuseria, G. E.; Robb, M. A.; Cheeseman, J. R.; Montgomery, J. A., Jr.; Vreven, T.; Kudin, K. N.; Burant, J. C.; Millam, J. M.; Iyengar, S. S.; Tomasi, J.; Barone, V.; Mennucci, B.; Cossi, M.; Scalmani, G.; Rega, N.; Petersson, G. A.; Nakatsuji, H.; Hada, M.; Ehara, M.; Toyota, K.; Fukuda, R.; Hasegawa, J.; Ishida, M.; Nakajima, T.; Honda, Y.; Kitao, O.; Nakai, H.; Klene, M.; Li, X.; Knox, J. E.; Hratchian, H. P.; Cross, J. B.; Bakken, V.; Adamo, C.; Jaramillo, J.; Gomperts, R.; Stratmann, R. E.; Yazyev, O.; Austin, A. J.; Cammi, R.; Pomelli, C.; Ochterski, J. W.; Ayala, P. Y.; Morokuma, K.; Voth, G. A.; Salvador, P.; Dannenberg, J. J.; Zakrzewski, V. G.; Dapprich, S.; Daniels, A. D.; Strain, M. C.; Farkas, O.; Malick, D. K.; Rabuck, A. D.; Raghavachari, K.; Foresman, J. B.; Ortiz, J. V.; Cui, Q.; Baboul, A. G.; Clifford, S.; Cioslowski, J.; Stefanov, B. B.; Liu, G.; Liashenko, A.; Piskorz, P.; Komaromi, I.; Martin, R. L.; Fox, D. J.; Keith, T.; Al-Laham, M. A.; Peng, C. Y.; Nanayakkara, A.; Challacombe, M.; Gill, P. M. W.; Johnson, B.; Chen, W.; Wong, M. W.; Gonzalez, C.; Pople, J. A. Gaussian 03, revision C.02; Gaussian, Inc.: Wallingford, CT, 2004.

(25) Murray, J. S.; Politzer, P. THEOCHEM 1998, 425, 107. (b) Politzer, P.; Murray, J. S. Trends Chem. Phys. 1999, 7, 157. (c) Politzer, P.; Murray, J. S. Fluid Phase Equil. 2001, 185, 129.

(26) Weigold, H. Fuel 1982, 61, 1021.

(27) Geneste, P.; Moulinas, C.; Olive, J. L. J. Catal. 1987, 105, 254

(28) Jian, M.; Kapteijn, F.; Prins, R. J. Catal. 1997, 168, 491.

(29) Desican, P.; Amberg, C. H. Can. J. Chem. Rev. 1964, 42, 843.

(30) Satterfield, C. N.; Modell, M.; Mayer, J. F. AIChE J. 1975, 21 , 1100

(31) Jian, M.; Prins, R. Catal. Today 1996, 30, 127.

(32) Galvagno, S.; Donato, A.; Neri, G.; Pietropaolo, J. Chem. Technol. Biotechnol. 1991, 50, 145.

(33) Talukdar, A. K.; Bhattacharyya, K. G.; Sivasanker, S. Appl. Catal. 1993, 96, 229.

(34) Neri, G.; Visco, A. M.; Donato, A.; Milone, C.; Malentacchi, M.; Gubitosa, G. Appl. Catal. A 1994, 110, 49.

(35) Edelman, M. C.; Maholland, M. K.; Baldwin, R. M.; Cowley, S. W. J. Catal. 1988, 111, 243.

(36) Machacek, H.; Kochloefl, K.; Kraus, M. Chem. Commun. 1966, 31,576 .

(37) Kim, S.C.; Massoth, F. E. Ind. Eng. Chem. Res. 2000, 39, 1705

(38) Massoth, F. E.; Kim, S. C. Ind. Eng. Chem. Res. 2003, 42, 1011.

(39) Topsøe, H.; Clausen, B. S.; Massoth, F. E. In Catalysis-Science and Technology; Anderson, J. R.; Boudart, M., Eds.; Spinger: New York, 1996.

(40) Travert, A.; Nakamura, H.; van Santen, R. A.; Cristol, S.; Paul, J. F.; Payen, E. J. Am. Chem. Soc. 2002, 124, 7084.

(41) Raybaud, P.; Hafner, J.; Kresse, G.; Kasztelan, S.; Toulhoat, H. J. Catal. 2000, 189, 129.

(42) Lauritsen, J. V.; Bollinger, M. V.; Lægsgaard, E.; Jacobsen, K. W.; Nørskov, J. K.; Clausen, B. S.; Topsøe, H.; Besenbacher, F. J. Catal. 2004, 221, 510 .

(43) Sun, M.; Nelson, A. E.; Adjaye, J. Catal. Today 2005, 105, 36.

(44) Logadottir, A.; Moses, P. G.; Hinnemann, B.; Topsøe, N.-Y.; Knudsen, K. G.; Topsøe, H.; Nørskov, J. K. Catal. Today 2006, 111, 44.

(45) Moreau, C.; Joffre, J.; Saenz, C.; Geneste, P. J. Catal. 1990, 122, 448.

(46) Volter, J.; Hermann, J.; Heise, K. J. Catal. 1968, 12, 307.

(47) Rodriguez-Arias, E. N.; Gainzq, A. E.; Hernandez, A. J.; Lobos, P. S.; Rurtte, J. Mol. Catal. A 1995, 102, 163.

(48) Singhal, G. P.; Espino, R. L.; Sobel, J. E. J. Catal. 1981, 67, 446.

(49) Bataille, F.; Lemberton, J. L.; Michaud, P.; Pérot, G.; Vrinat, M.; Lemaire, M.; Schulz, E.; Breysse, M.; Kasztelan, S. J. Catal. 2000, 191, 409.

(50) Pokorny, P.; Zdrazil, M. Collect. Czech. Chem. Commun. 1981, 46, 2185.

(51) Vogelzang, M. W.; Li, C.-L.; Schuit, G. C. A.; Gates, B. C.; Petrakis, L. J. Catal. 1983, 84, 170.

(52) Houalla, M.; Nag, N. K.; Sapre, A. V.; Broderick, D. H.; Gates, B. C. AIChE J. 1978, 24, 1015 .

(53) Mills, P.; Korlann, S.; Bussell, M. E.; Reynolds, M. V.; Ovchinnikov, M. V.; Angelici, R. J.; Stinner, C.; Weber, T.; Prins, R. J. Phys. Chem. A 2001, 105, 4418.

(54) Prins, R. Adv. Catal. 2001, 46, 399.

(55) Topsøe, N.-Y; Topsøe, H.; Massoth, F. E. J. Catal. 1989, 119, 252.

(56) Nelson, N.; Levy, R. B. J. Catal. 1979, 58, 485. 